\title{
Treatment for chronic ischaemia-induced bladder detrusor dysfunction using bone marrow mesenchymal stem cells: An experimental study
}

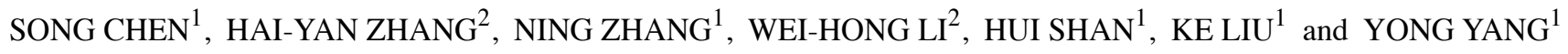 \\ ${ }^{1}$ Department of Urology, Beijing Chaoyang Hospital, Capital Medical University, Beijing 100020; \\ ${ }^{2}$ Department of Cell Biology, Municipal Laboratory for Liver Protection and Regulation \\ of Regeneration, Capital Medical University, Beijing 100069, P.R. China
}

Received September 8, 2011; Accepted October 26, 2011

DOI: $10.3892 / \mathrm{ijmm} .2011 .846$

\begin{abstract}
The mechanism of ischaemia-induced bladder dysfunction is not entirely clear, but is thought to be a result of the ischaemia-related M-receptor hypersensitivity to acetylcholine. In addition to nerve injury, ischaemia may cause bladder detrusor fibrosis and urethra de-epithelialization. Bladder dysfunctions caused by bladder outlet obstruction (BOO) and aging detrusor were considered to be associated with chronic ischaemia. To date, there has been no effective treatment for the histological and functional changes of the bladder caused by bladder ischaemia. The present study evaluated the feasibility and effectiveness of using bone marrow mesenchymal stem cells in the treatment of chronic ischaemia-induced bladder detrusor dysfunction in an experimental model. Bone marrow mesenchymal stem cells from Sprague-Dawley (SD) rats were injected into the common iliac artery of experimental animals, then bilateral iliac arteries were ligated and doxazosin mesylate was intragastrically administered. Eight weeks later, urodynamic examination and intravesical pressure measurements were performed on experimental animals. Histological changes of the taken bladder from sacrificed SD rats were evaluated by immunohistochemistry and trichrome staining and the images captured were analyzed by a software program. The average intravesical pressure and detrusor contraction power of the ischaemia group was $16.21 \pm 5.26$ and $17.26 \pm 5.72$; those of the experimental group were $24.02 \pm 10.06$ and $25.84 \pm 11.99$; the average intravesical pressure and detrusor contraction power of the control group was $28.56 \pm 4.48$ and $29.57 \pm 5.01$. The average intravesical pressure and detrusor contraction power of the ischaemia group were significantly lower than those of the experimental and control group, while no significant difference was shown between the experimental
\end{abstract}

Correspondence to: Dr Yong Yang, Department of Urology, Beijing Chaoyang Hospital, Capital Medical University, No. 8, Gongti South Road, Chaoyang District, Beijing 100020, P.R. China E-mail: yoya@china.com

Key words: stem cell, bladder, chronic ischaemia and control groups. 5-Bromo-2'-deoxyuridine (BrdU) staining for the experimental group was positive. The percentage of the smooth muscle content in the bladder wall was $(25.21 \pm 6.28) \%$, $(49.38 \pm 6.32) \%$ and $(48.00 \pm 17.39) \%$ for ischaemia, experimental and control group, respectively. The percentage of smooth muscle in the bladder wall of the ischaemia group was significantly lower than that of the experimental and control group, while no significant difference was observed between the experimental and control groups. The number of nerve fibers per high power field of the experimental group was significantly higher than that of the ischaemia group, but lower than the control group. In conclusion, the percentage of smooth muscle content and the number of nerve cells per high power field decreases in ischaemia bladder, with detrusor contractility decreased. Injection of stem cell suspension into the common iliac artery in rats with ischaemic bladder, followed by intragastric administration of doxazosin mesylate, makes transplanted stem cells regenerate in the bladder tissue, increases the percentage of smooth muscle content and nerve cells per high power field in the bladder wall, and improve bladder detrusor contraction function.

\section{Introduction}

The cause of bladder dysfunction, urinary incontinence and lower urinary tract symptoms (LUTS) has not yet been fully understood. LUTS prevalence in women over 50-years-old is $36 \%$ and increases with aging (1). In men, LUTS was always thought to be caused by bladder outlet obstruction (BOO), benign prostatic hyperplasia $(\mathrm{BPH})$ for example. However, $1 / 3$ of the cases had no BOO (2). Urodynamic examination demonstrated that the age-specific changes of bladder function existed in both men and women. Pathophysiology of LUTS was gender-neutral but age-related, affecting bladder smooth muscle, urothelium, blood vessels and/or nerve. The incidence of these effects increases with age (3). Transrectal colour Doppler ultrasound examination showed that bladder blood irrigation in elderly LUTS patients was significantly lower than in younger healthy controls, with no gender differences (4). In addition, $\alpha$-receptor blocker ( $\alpha$-blocker) was reported to improve the chronic ischaemic conditions and symptoms in 
LUTS patients. It is thus indicated that chronic ischaemia is closely related with LUTS (5).

Atherosclerosis-induced chronic bladder ischaemia study in an animal model showed that there were apparent changes in bladder structure and function $(3,6)$. The most important pathological changes were bladder fibrosis and smooth muscle component resulting in lower bladder compliance. In moderate ischaemia bladder, the main characteristic was detrusor overactivity with increase of detrusor contraction by urodynamic examination. In severe ischaemia bladder, intravesical pressure decreased. These studies confirmed that chronic ischaemia is a major cause of bladder dysfunction. Although $\alpha$-blockers can improve the patient's LUTS, damaged ischaemic bladder smooth muscle and nerve tissue cannot regenerate (7). In clinical practice, there is a lack of effective therapy for chronic bladder ischaemia. In recent years, a series of studies found that direct injection of muscle and fat-derived cells into an artificial damaged bladder wall of experimental animals, can make implanted stem cells evolve into mature smooth muscle cells (8-11). Therefore, stem cell treatment opened up a new way in repairing injured bladder tissues. In the current study, bone marrow mesenchymal stem cells were transplanted into chronic ischaemic rats with concurrent intragastric administration of doxazosin mesylate. We investigated the capacity of stem cells generating into bladder smooth muscle cells and the feasibility and effectiveness of this method in the treatment of chronic bladder ischaemia. Moreover, we hypothesized that doxazosin mesylate may enhance the capacity of stem cells generating into detrusor cells through improving bladder blood flow.

\section{Materials and methods}

Experimental animals and study design. Four-month-old female SD rats were subjected to bilateral iliac artery ligation, in order to establish a chronic bladder ischaemia model. All rats were originally purchased from Beijing Vital River Laboratories and protocols were reviewed and approved by the local ethics committee. Stem cell suspensions were injected into the unilateral side of the iliac artery in experimental rats with bilateral iliac artery ligation. Bladder samples from these rats were tested using immunohistochemistry staining to verify the viability of the transplanted stem cells in the tissues. From the rats which showed success in stem cell transplantation 30 were selected and divided into 3 groups of 10 each: i) ischaemic group: bilateral iliac artery ligation for bladder ischaemia; ii) experimental group: stem cell suspension into the unilateral side of the iliac artery with ligation of bilateral iliac artery afterwards; iii) control group: same surgery was performed but without stem cell injection and ligation of the bilateral iliac arteries (sham operation).

After 8 weeks, experimental animals received urodynamic examinations to record detrusor contraction pressure and the duration of each contraction. At the conclusion of the experiments, all subjects were sacrificed after urodynamic examination. Bladder tissues were taken and examined using histological and immunohistological methods for BrdU, Masson's trichrome and S-100 staining. The sections were photographed and stem cell growth within the bladder wall observed. Masson's trichrome staining of bladder smooth muscle and nerve cells per high power field in S-100 stain film image were calculated by Image-Pro Plus (IPP) (MediaCybernetics, USA) image analysis software. Finally, SPSS 11.0 statistical software (SPSS Inc., Chicago, IL) was used to analyze the urodynamic, smooth muscle and nerve cells, to analyze the histological changes in ischaemic bladder wall and detrusor function after stem cell transplantation.

Establishment of a chronic bladder ischaemia model in SD rats, pre-study results and establishment of experimental rats. Experimental animals from 4-month-old female SD rats were divided into 3 groups: control, ischaemic and experimental (stem cells and doxazosin mesylate combined treatment group). In the control group only the sham operations were carried out without stem cell injection and ligation of bilateral iliac arteries. A urodynamic examination was conducted after 8 weeks, then the animals were sacrificed and bladder tissue was taken and paraffin sections were subjected to immunohistochemistry. Rats in the ischaemic group received anesthesia with $20 \%$ urethane solution cervical subcutaneously, at a dose of $0.6 \mathrm{ml} / 100 \mathrm{~g}$ body weight. A lower abdominal transverse incision was made into the unilateral side of the iliac fossa, pushing the peritoneum aside, isolating iliac and external iliac artery and vein, revealing the internal iliac artery and vein and ligating the bilateral iliac arteries. The contralateral iliac artery was ligated with the same method.

Of the 30 rats in the pre-study, one got unilateral hindlimbs stiff and disabled, some of the animals had temporary purple and limp unilateral hindlimbs (mostly in 3 days post-operation), and recovered later. None of the rats had necrosis of the bilateral lower extremities or death. Eight weeks after surgery, the bladder tissues of the rats in the control and ischaemia groups were removed. Under Masson's trichrome staining, the bladder smooth muscle of the normal control rats was in neat rows with a higher proportion of muscle fibers. A reduced proportion of smooth muscle was shown in the bladder of ischaemic rats, with muscle fiber disordered and a significant increase of fibrous tissue in the intramuscular and submucosal tissue (Fig. 1). The result was consistent with the characteristics of chronic ischaemia and aging detrusor $(3,12)$, and these rat models in our pre-study experiments were established as the chronic bladder ischaemia model in further study. In the experimental group of SD rats in pre-study, BrdU-labeled stem cell suspension was injected into the iliac artery. Before injection, the ipsilateral external iliac artery was clipped close to the artery bifurcation. After injection, the iliac artery was ligated at the distal and proximal puncture sites, respectively. The contralateral iliac artery was ligated as well. The bladder tissues of the rats were removed after 8 weeks of sacrificing. A very small number of BrdU-positive (Nigger-brown nuclei) cells could be seen in bladder smooth muscle (Fig. 2), suggesting that only a low number of transplanted stem cells in the ischaemic bladder tissue regenerated. A possible reason may be that severe ischaemia blocks stem cell growth. With repeated experiments, experimental rats were fed by doxazosin mesylate (instillation into the stomach) with a daily dose of $10 \mathrm{mg} / \mathrm{kg}$ body weight for 8 weeks, which could improve blood supply to the bladder $(13,14)$. After that many more stem cells survived (Fig. 5). This method will be used to establish an experimental animal model in further study. 


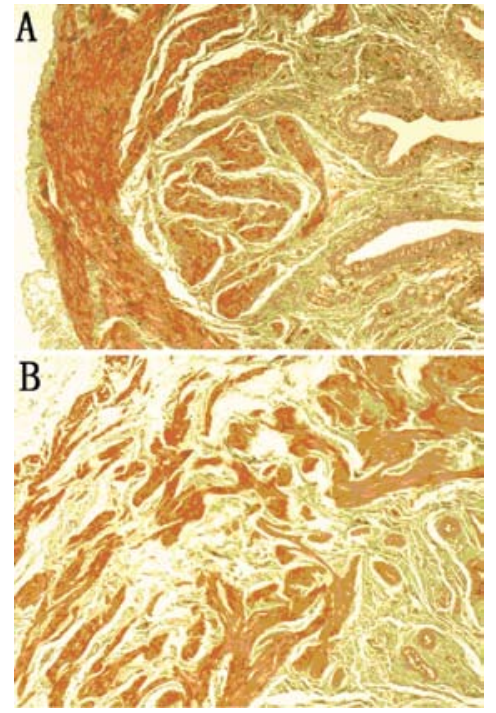

Figure 1. Bladder wall Masson's trichrome stain, magnification x200. (A) Control group bladder smooth muscle (orange region) in neat rows with higher proportion of muscle fibers. (B) Ischaemia group bladder smooth muscle fiber disordered, with a reduced proportion of smooth muscle, and a significant increase of fibrous tissue in the intramuscular and submucosal region (green).
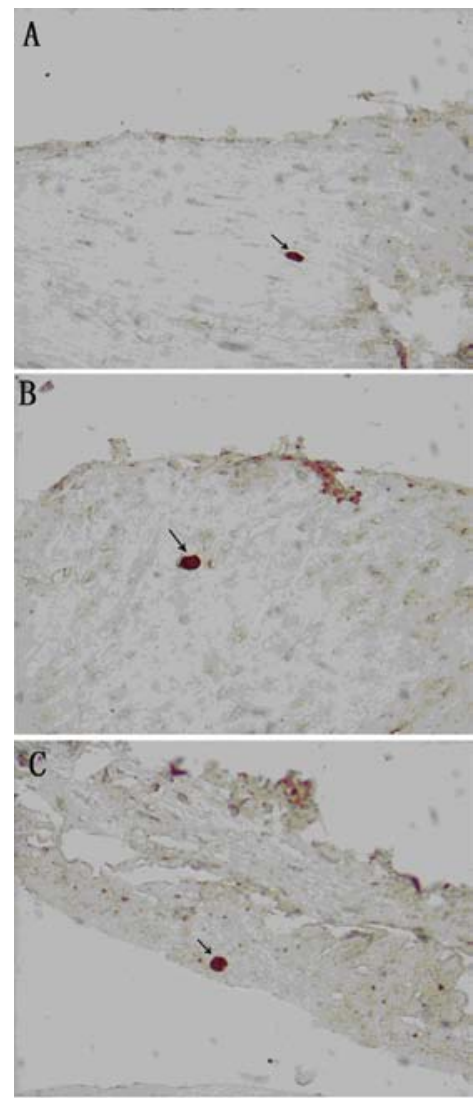

Figure 2. Bladder tissue BrdU strain. A very small number of BrdU-positive (Nigger-brown nuclei) cells can be seen in bladder smooth muscle in all panels.

Bone marrow mesenchymal stem cell preparation. Rat bone marrow mesenchymal stem cells (BMSC) obtained from donor male SD rats (3-4-weeks-old) were incubated in $\mathrm{HyQ}^{\circledR}$ MEM Alpha Modification (HyClone, USA) with $10 \%$ fetal bovine serum (Gibco, USA) and 1\% antibiotics (penicillin-

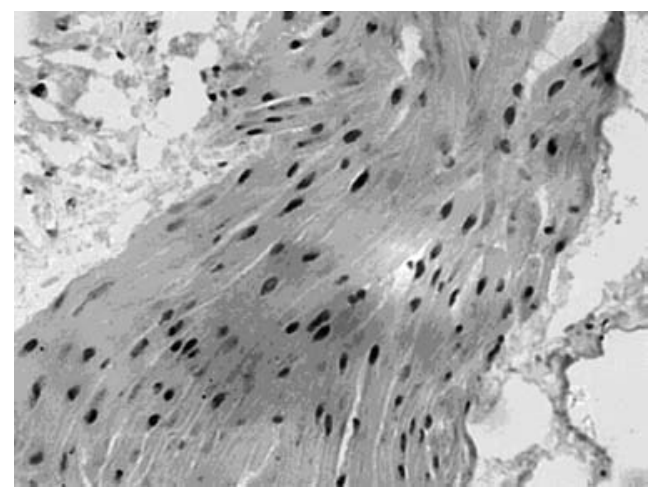

Figure 3. BrdU staining in experimental group. BrdU-positive (Nigger-brown nuclei) cells percentage of content of smooth muscle.

streptomycin; Gibco) and maintained at $37^{\circ} \mathrm{C}$ in $5 \% \mathrm{CO}_{2} / 95 \%$ ambient mixed air. Prior to injection, BMSCs were labeled with $\operatorname{BrdU}(30 \mu \mathrm{g} / \mathrm{ml}$; Sigma-Aldrich, USA) in vitro for 3 days, and the cultured medium was collected with $4 \times 10^{6}$ cells/tube, and stored at $4^{\circ} \mathrm{C}$. This stem cell suspension was then visualised by BrdU staining. Only the BrdU positive populations were used.

Urodynamic examination. Analysis was performed with the urodynamic measurement system UDS-120XLT, (Laborie Medical Technologies Inc., Canada) as previously described $(15,16)$. An intravenous catheter was used as cystometry catheter. Rats in a supine position with secured limbs, had a catheter inserted into the bladder with room-temperature normal saline. The bladder was irrigated with normal saline at a speed of $90 \mathrm{ml} / \mathrm{h}$ for pressure measurement. The curve images with 5 min perfusion under a resting state were collected, which recorded the wave amplitude and the duration of each contraction wave at that period. Average detrusor pressure was calculated. To calculate detrusor contraction power, in each of the urodynamic curves, it was denoted that $\mathrm{P}$ was equal to the absolute value of maximum pressure wave of a contraction wave, $\mathrm{T}$ was equal to the absolute value of the duration of the contraction wave, then $\mathrm{W}$ was equal to $\mathrm{P} \mathrm{x}$ $\mathrm{T}$ which indicates the work of one detrusor contraction. The whole detrusor power per time unit in this $5 \mathrm{~min}$ recording was equal to $\mathrm{WxN} /(\mathrm{T} 1+\mathrm{T} 2+\ldots . \mathrm{Tn})$, which was denoted as detrusor contraction power, and $\mathrm{N}$ indicted the number of detrusor contraction in this 5 min curve. Using detrusor contraction power, made it easier and more sensitive to express the power of detrusor contraction when analysing the data.

Immunohistochemical staining. Animals were sacrificed after cystometry, bladder tissues were obtained and fixed with $4 \%$ formalin. Paraffin sections were made from the tissues and used for immunofluorescence staining. BrdU staining was used to determine the successful regeneration of transplanted bone marrow stem cells in the bladder. Briefly, after sectioning, the bladder sample was paraffin de-waxed to the water, and sealed by $0.3 \% \mathrm{H}_{2} \mathrm{O}_{2}$ and $2 \mathrm{~N} \mathrm{HCl}$ was used to denature DNA, followed by digesting the samples with pepsin. Then the section was sealed by reagent A (10\% normal goat serum); titrating BrdU-specific monoclonal antibody (Sigma-Aldrich), reagent $\mathrm{B}$ and $\mathrm{C}$, respectively; the section was DAB-stained, 


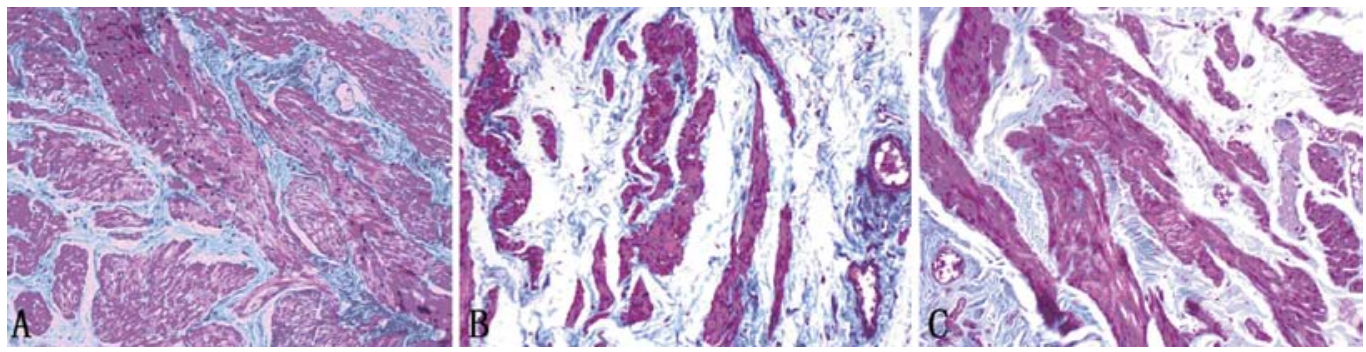

Figure 4. Masson's trichrome staining; magnification $\mathrm{x} 400$. Percentage of content of bladder smooth muscle (red area) in (A) the control and (C) the experimental group was significantly higher than that in (B) the ischaemic group. Blue area represents the fibrous connective tissue.

hematoxylin-eosin restained and dehydrated and sealed. The distribution of bladder detrusor (red stain) and fibrous tissue (blue stain) was analysed by Masson's trichrome stain. Briefly, after sections were paraffin dewaxed to the water, the section was nuclear stained by Weigert's hematoxylin, then restained by acid fuchsin and light green, and finally dehydrated and sealed for further study. The distribution of nerve fibers in the bladder tissue was analyzed by S-100 staining. After the section was paraffin dewaxed to water, the section was treated with antigen, high pressure fixed with $\mathrm{pH} 6.0$ citric acid and sealed with $3 \% \mathrm{H}_{2} \mathrm{O}_{2}$. S-100 protein was chosen as the first antibody to label nerve fibers in bladder tissue. This was followed by treatment with the polymer detection kit, before the sections were DAB-stained, hematoxylin-eosin restained, dehydrated and sealed for further study.

Image and data analysis. Five views of each tissue section were chosen for photography under a x400 magnification for data analysis. The distributions of bladder detrusor (red stain) and fibrous tissue (blue stain) were analyzed by the Masson's trichrome stain. IPP (MediaCybernetics) was used to calculate the percentage of red stain and blue stain area per high power field, which represents the proportion of smooth muscle in the bladder tissue. The distribution of nerve fibers in the bladder tissue was analysed by S-100 staining. Positive staining was defined as dark-brown nuclei of nerve fibers. The results are shown as the number of positive nuclei per high power field.

Statistical analysis. SPSS11.0 was used for statistical analysis. Mainly the Student's t-test was used to analyse the following parameters: i) average percentage of smooth muscle per high power field among all 3 groups; ii) average S-100-positive nuclei number per high power field in all 3 groups and iii) average contraction of detrusor and contraction power in all 3 groups. $\mathrm{P}<0.05$ was considered to indicate statistical significance.

\section{Results}

BrdU staining. After administration of doxazosin mesylate, tissues from the experimental group were positive for BrdU staining (Fig. 3). The number of positive BrdU-stained cells was higher than in the pre-study experiment. After stem cell transplantation alone, there were very low numbers of positive BrdU-stained cells in pre-study (Fig. 2).

Percentage of smooth muscle content. The typical expression of Masson's trichrome stain in the control group, ischaemia group

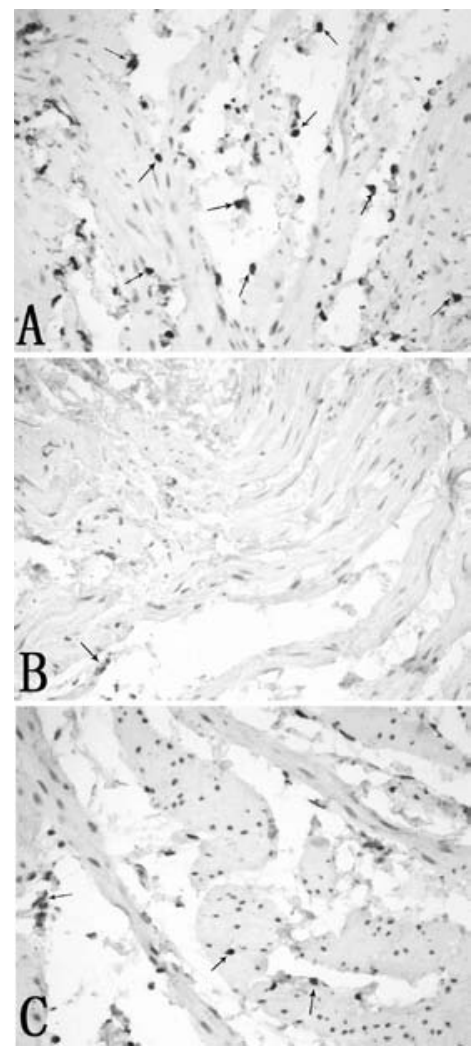

Figure 5. Bladder wall nerve tissue of (A) the control group, (B) the ischaemia group and (C) the experimental group was stained by $\mathrm{S}-100$; magnification, $\mathrm{x} 400$. The number of S-100 positive neuronal cell nuclear (dark brown) per high power field in experimental group was significantly higher than in the ischaemic group, but lower than in the control group; The number of S-100 positive cells in the ischaemia group was significantly lower than in the control group.

and experimental group is shown in Fig. 4. The percentage of smooth muscle content in the control group and the experimental group was significantly higher than that in the ischaemia group, while there was no significant difference between the control and the experimental groups (Table I).

Nerve fiber content. By immunohistochemical methods, using S-100 protein as an anti-tag staining to stain the nervous tissue of the bladder wall, the number of positive cells per high power field in the control and experimental groups was significantly higher than that in the ischaemic group. The number of positive cells in the experimental group was significantly lower than that of the control group (Fig. 5). 

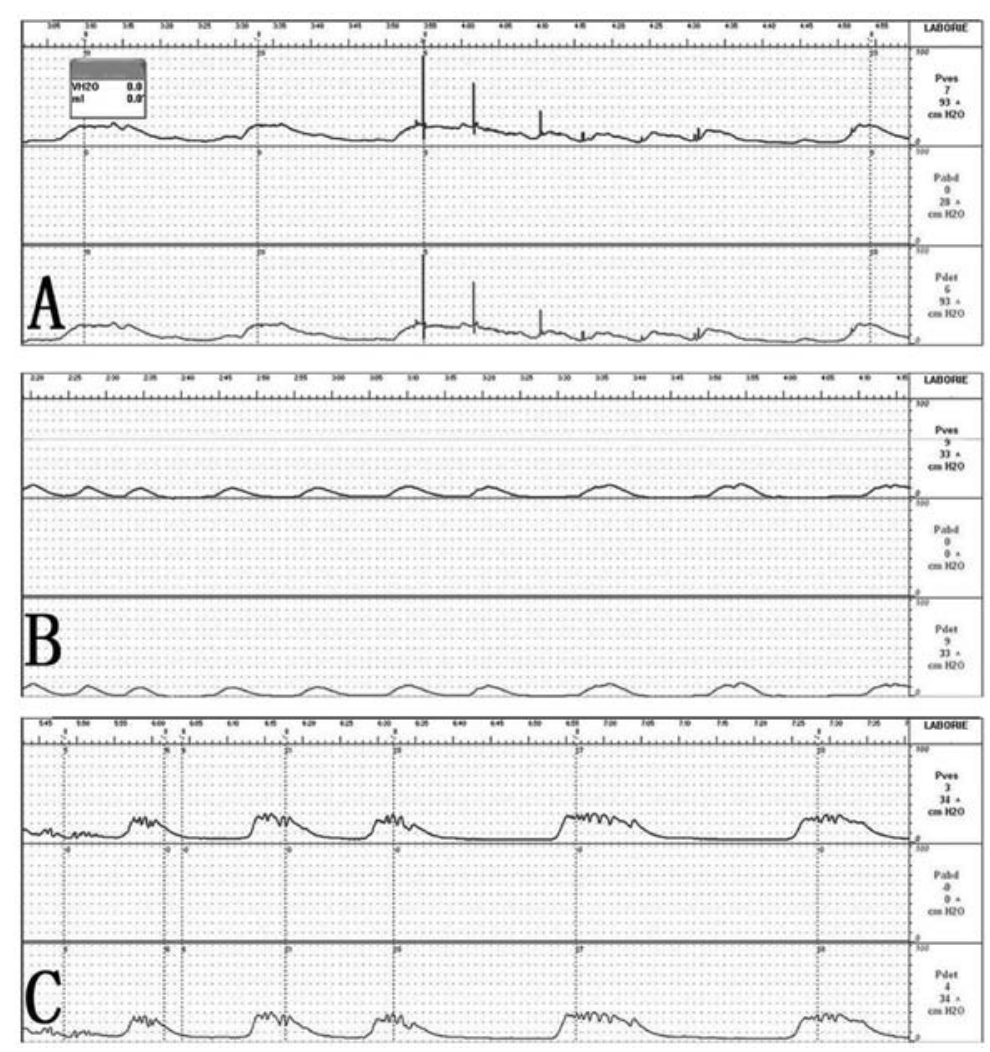

Figure 6. Urodynamic curve (A) of the control group, (B) the ischaemia group and (C) the experimental group. The curve shows the intravesical pressure. Intravesical pressure in the control group and experimental group was significantly higher than in the ischaemic group, while there was no significant difference between the control group and the experimental group.

Table I. Urodynamic and staining results.

\begin{tabular}{lccc}
\hline Groups & $\begin{array}{c}\text { Control, } \\
\text { mean } \pm \text { SD }\end{array}$ & $\begin{array}{c}\text { Ischaemia, } \\
\text { mean } \pm \text { SD }\end{array}$ & $\begin{array}{c}\text { Experimental, } \\
\text { mean } \pm \text { SD }\end{array}$ \\
\hline Urodynamic & & & $24.02 \pm 10.06^{\mathrm{a}}$ \\
Pressure & $28.56 \pm 4.483^{\mathrm{a}}$ & $16.21 \pm 5.26^{\mathrm{b}}$ & $25.84 \pm 11.99^{\mathrm{a}}$ \\
Power & $29.57 \pm 5.01^{\mathrm{a}}$ & $17.26 \pm 5.72^{\mathrm{b}}$ & \\
Staining & & & $49.38 \pm 6.32^{\mathrm{a}}$ \\
Smooth muscle & $48.00 \pm 17.39^{\mathrm{a}}$ & $25.21 \pm 6.28^{\mathrm{b}}$ & $9.30 \pm 3.31^{\mathrm{a}}$ \\
Nerve fiber & $13.98 \pm 4.61^{\mathrm{a}}$ & $4.41 \pm 1.45^{\mathrm{b}}$ & \\
\hline
\end{tabular}

All data are expressed as means \pm SD. The mean difference is significant at the 0.05 level. a Significant differences from the ischaemia group. ${ }^{\mathrm{b}}$ Significant differences from the control group.

Urodynamic result. Fig. 6 shows the typical curve of urodynamic bladder pressure in each group. The intravesical pressure in the ischaemia group was significantly lower than in the experimental and control groups (Table I). With approximate calculation, the bladder detrusor contraction power in the ischaemia group was significantly lower than in the experimental and control groups. There was no significant difference between the control and the experimental groups (Table I).

\section{Discussion}

For elderly patients, it has been confirmed that chronic bladder ischaemia is one of the important reasons causing
LUTS (6). Several studies (17) showed that artery stenosis and blood insufficiency, commonly seen in the elderly, can cause significant changes of bladder structure and function. Pathological changes in bladder tissue depend on the severity of arterial stenosis and bladder ischaemia. The mechanism of ischaemia-induced bladder dysfunction is complicated, which may be related to ischaemic denervation. This causes M-cholinergic receptor hypersensitivity to acetylcholine (18) and results in detrusor overactivity which leads to more ischaemia in the bladder wall. The current study attempted to implant stem cells into the bladder wall as means to improve the pathological changes caused by ischaemia and improve the function of ischaemic bladder. In our study, we found that the 
pathological and functional changes of the bladder ischaemic model are similar to human aging detrusor. It is suggested that the ischaemia rat model could also be used for LUTS which caused by aging detrusor.

For ease of urodynamic urethral catheter insertion during urodynamics, we usually select female SD rat to establish our rat model. As reported in the literature (3), after unilateral bladder artery ligation in rabbits, the bladder function caused by ischaemia is recovered in 4 weeks, which may be related to the establishment of collateral circulation; while bilateral bladder artery ligation leads to lasting changes in bladder structure and function. In our pre-study, the internal iliac artery was found to be extremely thin in the rats, which caused difficulties in injection of a stem cell suspension into the internal iliac artery. Therefore, the common iliac artery was selected for ligation and injection of the stem cells in suspension. Eight weeks after bilateral iliac artery ligation, the percentage of smooth muscle content and the number of nerve fibers per high power field in the ischaemic bladder were significantly decreased compared to the control group (Figs. 1,4 and 5), while bladder muscle contraction decreased (Fig. 6, Table I); No rats had necrosis of the lower limb ischaemia or postoperative death in the study. The results suggests that ligation of the bilateral common iliac arteries is feasible and reliable for the chronic ischaemic bladder rat model.

In previous studies using stem cell transplantation for the treatment of bladder dysfunction or the injury model in mice and rats $(11,12)$, the stem cells were transplanted by direct injection into the bladder wall or intravenous injection to the caudal vein. The results showed that direct injection of stem cells into the bladder wall is more effective than the intravenous injection to the caudal vein (12). In the pre-experiment, 8 weeks after injection of stem cells into the common iliac artery and bilateral common iliac artery ligation, a very small number of stem cells was still visible within the bladder wall by BrdU staining, thus confirming the growth of stem cells in bladder tissue. Moreover, stem cells spread over the bladder wall with 8 weeks administration of doxazosin mesylate and ligation bilateral of the common iliac artery, as detected by BrdU stain. This would suggest that the growth of stem cell within the bladder tissue clearly improves the severe ischaemia condition. Therefore, the transplanted stem cells introduced by injection to the common iliac artery will be regenerated in the ischaemic bladder with the treatment of doxazosin mesylate in the rat. This method not only effectively establishes the ischaemia bladder model in the rat, it also serves as a method for vascular-mediated stem cell transplantation for the treatment of large animals, and may have important implications in the treatment of human bladder dysfunction in the future.

The percentage of smooth muscle content in the ischaemia group was significantly lower than in the control and experimental groups, while there was no significant difference between the control and experimental groups, suggesting that improvement of bladder ischaemia with stem cell transplantation can reduce the extent of the damage of tissue structure in bladder, and may be beneficial for stem cells to differentiate into smooth muscle cells. The number of nerve fiber in the ischaemia group was significantly lower than in the experimental and control groups. The number of nerve fibers in the experimental group was significantly higher than in the ischaemia group and the number of nerve fiber in the experimental group decreased compared to the control group, suggesting that neural tissue tolerance for ischaemia was lower than that of smooth muscle and more difficult to regrow. We believe that the reversed changes of the percentage of smooth muscle content and the number of nerve fibers in the bladder wall may be associated with the regeneration of the stem cells injected. The results from our study show that administration of doxazosin mesylated could improve the survival rate of stem cell transplantation and both together could repair the function of ischaemic bladder, but whether doxazosin mesylate could have a sole effect on the ischaemia bladder remains to be further evaluated.

Detrusor contraction pressure and power were significantly lower in the ischaemia group than in the experimental and control groups, while there was no significant difference between the experimental and control groups, suggesting that changes of detrusor function are consistent with the changes of the percentage of smooth muscle content and the number of nerve fibers. For the evaluation of detrusor contraction, maximum watts factor is an objective indicator, not impacted by bladder outlet obstruction and can be used for detrusor function assessment, wether or not the patients had bladder outlet obstruction (19). Assessment of the watts factor is complex, as it requires multiple urodynamic parameters, such as intravesical pressure, urethral pressure and even flow rate. It is difficult to assess the watts factor by urodynamic examination in an animal model (rats, for example). Under the current experimental condition, we were only able to measure the intravesical pressure. With these considerations, we calculated approximate detrusor contraction power based on existing data. The area between the detrusor pressure curve and the time in the period can represent detrusor contraction power as mentioned above.

The exact mechanism for bone marrow stem cells to improve bladder detrusor dysfunction is still not clear. A previous study showed that fat-derived stem cells can improve the bladder overactivity in high-fat-diet-induced rat (12). A possible reason may be the direct differentiation of stem cells to associated smooth muscle, nerve cells and blood vessels in the bladder. It has been shown that stem cells excrete active substances and growth factors, which may stimulate the growth of blood vessels in the bladder in a paracrine form. Thus, bone marrow mesenchymal stem cells can be divided into bone and cartilage cells, muscle cells, fat cells and other tissue cells (20). The animal study using bone marrow stem cells in treating myocardial infarction confirmed that stem cells not only differentiate into cardiac cells and vascular cells, but also activate cardiac stem cells by, via the paracrine route, secreting active substances and growth factors (21). A study using bone marrow stem cells in cerebral ischaemia treatment found that, stem cells can improve the neurological function of ischaemic tissue and strengthen the expression of IL-10, which has neuroprotective effects (22).

In conclusion, the percentage of smooth muscle content and the number of nerve cells decreases in ischaemia bladder, with a decrease in detrusor contractility. Injection of a stem cell suspension into the common iliac artery in rats with ischaemic bladder, followed by intragastric administration of doxazosin mesylate, makes transplanted stem cells regenerate in the bladder tissue, increases the percentage of smooth muscle 
content and of nerve cells per high power field in the bladder wall, and improves bladder detrusor contraction function.

\section{Acknowledgements}

This study was supported by the National Natural Science Foundation of China, grant no. 30840084.

\section{References}

1. Heidler S, Deveza C, Temml C, Ponholzer A, Marszalek M, Berger I, Bluhhm A and Madersbacher S: The natural history of lower urinary tract symptoms in females: analysis of a health screening project. Eur Urol 52: 1744-1750, 2007.

2. Yang Y, Wu SL, Duan JH, Pan BN, Na YQ and Guo YL: Evaluation of detrusor function with urodynamics and treatment choice. Chin J Surg 39: 299-301, 2001 (In Chinese).

3. Azadzoi KM, Tarcan T, Kozlowski R, Krane RJ and Siroky MB Overactivity and structural changes in the chronically ischemic bladder. J Urol 162: 1768-1778, 1999.

4. Pinggera GM, Mitterberger M, Steiner E, Pallwein L, Frauscher F, Aigner F, Bartsch G and Strasser H: Association of lower urinary tract symptoms and chronic ischaemia of the lower urinary tract in elderly women and men: assessment using colour Doppler ultrasonography. BJU Int 102: 470-474, 2008.

5. Ping gera GM, Mitterberger M, Pallwein L, Schuster A, Herwig R, Frauscher F, Bartsch G and Strasser H: $\alpha$-Blockers improve chronic ischaemia of the lower urinary tract in patients with lower urinary tract symptoms. BJU Int 101: 319-324, 2008.

6. Azadzoi KM, Tarcan T, Siroky MB and Krane RJ: Atherosclerosisinduced chronic ischemia causes bladder fibrosis and non-compliance in the rabbit. J Urol 161: 1626-1635, 1999.

7. Chancellor MB, Yoshimura N, Pruchnic R and Huard J: Gene therapy strategies for urological dysfunction. Trends Mol Med 7: 301-306, 2001.

8. Yokoyama T, Pruchnic R, Lee JY, Chuang YC, Jumon H, Yoshimura N, de Groat WC, Huard J and Chancellor MB Autologous primary muscle-derived cells transfer into the lower urinary tract. Tissue Eng 7: 395-404, 2001.

9. Huard J, Yokoyama T, Pruchnic R, Qu Z,Li Y,Lee JY, Somoqyi GT, de Groat WC and Chancellor MB: Muscle-derived cell-mediated ex vivo gene therapy for urological dysfunction. Gene Ther 9: $1617-1626,2002$.
10. Pruchnic R, Yokoyama T, Lee JY, Huard J and Chancellor MB: Muscle derived cell mediated ex vivo gene transfer to the lower urinary tract: comparison of viral vectors. Urol Res 30: 310-316, 2002.

11. Sakuma T, Matsumoto T, Kano K, Fukuda N, Obinata D, Yamaguchi K, Yoshida T, Takahashi S and Mugishima H: Mature, adipocyte derived, dedifferentiated fat cells can differentiate into smooth muscle-like cells and contribute to bladder tissue regeneration. J Urol 182: 355-365, 2009.

12. Huang YC, Shindel AW, Ning H, Lin G, Harraz AM, Wang G, Garcia M, Lue TF and Lin CS: Adipose derived stem cells ameliorate hyperlipidemia associated detrusor overactivity in a rat model. J Urol 183: 1232-1240, 2010.

13. Das AK, Leggett RE, Whitbeck C, Eagen G and Levin RM: Effect of doxazosin on rat urinary bladder function after partial outlet obstruction. Neurourol Urodyn 21: 160-166, 2002.

14. Yono M, Yamamoto Y, Yoshida M, Ueda S and Latifpour J: Effects of doxazosin on blood flow and mRNA expression of nitric oxide synthase in the spontaneously hypertensive rat genitourinary tract. Life Sci 81: 218-222, 2007.

15. Patra PB, Thorneloe KS and Laping NJ: Effect of estrogen and progesterone on urodynamics in the conscious rat. Urology 74 : 463-466, 2009.

16. Hedlund P, Streng T, Lee T and Andersson KE: Effects of tolterodine on afferent neurotransmission in normal and resiniferatoxin treated conscious rats. J Urol 178: 326-331, 2007.

17. Azadzoi KM: Effect of chronic ischemia on bladder structure and function. Adv Exp Med Biol 539: 271-280, 2003.

18. Abrams $\mathrm{P}$ and Andersson KE: Muscarinic receptor antagonists for overactive bladder. BJU Int 100: 987-1006, 2007.

19. Lecamwasam HS, Yalla SV, Cravalho EG and Sullivan MP: The maximum watts factor as a measure of detrusor contractility independent of outlet resistance. Neurourol Urodyn 17: 621-635, 1998.

20. Smits AM, van Vliet P, Hassink RJ, Goumans MJ and Doevendans PA: The role of stem cells in cardiac regeneration. J Cell Mol Med 9: 25-36, 2005.

21. Makino S, Fukuda K, Miyoshi S, Konishi F, Kodama H, Pan J, Sano M, Takahashi T, Hori S, Abe H, Hata J, Umezawa A and Ogawa S: Cardiomyocytes can be generated from marrow stromal cells in vitro. J Clin Invest 103: 697-705, 1999.

22. Li J, Zhu H, Liu Y, Li Q, Lu S, Feng M, Xu Y, Huang L, Ma C, An Y, Zhao RC, Wang R and Qin C: Human mesenchymal stem cell transplantation protects against cerebral ischemic injury and upregulates interleukin-10 expression in Macacafascicularis. Brain Res 1334: 65-72, 2010. 